\title{
Doctoral programs in geography in the United States
}

\author{
Susan M. Roberts
}

(C) Springer Science+Business Media Dordrecht 2014

\begin{abstract}
This short intervention provides a snap shot of key concerns, developments, and challenges in the doctoral programs currently provided by Geography Departments in universities in the United States. It profiles overarching trends in recruitment and graduations, charts the standard routes students navigate through, documents the ever more systematic effort to provide greater professionalization for students and reflects upon the ramifications of the economic recession for doctoral students.
\end{abstract}

Keywords $\mathrm{PhD} \cdot$ United States ·

Professionalization · Geography

There are presently 68 universities in the United States offering PhD degrees in Geography. Recent years have each seen over 200 geographers graduate with doctoral degrees in the US. But, given that there are over $150,000 \mathrm{PhDs}$ awarded annually in the US including in medicine and law (NCES 2011), and close to 50,000 in the more narrowly defined categories of the National Science Foundation, Geography appears as a minor discipline whose data can easily get lost in

S. M. Roberts $(\square)$

Department of Geography, University of Kentucky,

Lexington, KY 40506-0027, USA

e-mail: geg207@uky.edu the national level surveys of doctoral education (NSF 2010; Thurgood et al. 2006). In such surveys, physical geography $\mathrm{PhDs}$ may be aggregated under Earth Sciences, whereas human geography $\mathrm{PhDs}$ may be folded into a Social Sciences category, adding to the difficulty of working with national data to ascertain the situation for Geography.

What we know is that in the US, Geography $\mathrm{PhD}$ programs are predominantly found in public universities, notably the nation's land-grant institutions, though there are a handful of programs at private universities (Solís et al. 2014). As is the pattern for $\mathrm{PhDs}$ in all fields, programs in the populous states of California, New York, and Texas together account for about one quarter of the total number of $\mathrm{PhDs}$ awarded in Geography (NSF 2010; AAG 2011). Most PhD programs in Geography award less than ten degrees per year. In 2010-2011 only three programs reported awarding more than ten doctorates (University of California Santa Barbara; Clark University; Texas State University) (AAG 2011). There are no data on the numbers of doctorates each year in the subdisciplines though, so while there are likely to be different trends in physical geography and human geography, and the number of PhDs awarded to those specializing in some aspect of Geographic Information Science is on the rise, the exact nature of the trends is hard to discern. However, overall, in terms of the national $\mathrm{PhD}$ scene, ours is a small discipline and most Geography doctoral programs in the US produce only a few PhDs per year. 
The number of Geography PhDs granted annually has been increasing and there has been some progress toward gender equity. In 2004-2005, $60 \%$ of PhDs in Geography went to men, while in 2009-2010 men earned $53 \%$ of Geography doctorates (AAG 2006; Solís and Adams 2011) There are still very few nonwhites earning Geography's highest degree in the US. Though robust and accessible data are conspicuously lacking, despite much concern about the situation, it is sobering that overall the situation may not have improved much since the AAG's Diversity Task Force reported in 2006 that: "In 2004, of the $144 \mathrm{PhD}$ degrees awarded in geography to American citizens and non-U.S. permanent residents, only $1(0.69 \%)$ was awarded to a Native American. Asian Americans were awarded 4 (2.8\%) and 3 (2.1\%) of PhD degrees were awarded to Blacks and Hispanics respectively. Whites, on the other hand, were awarded 124 , or $86 \%$, of the doctorate degrees" (AAG DTF 2006). A followup survey conducted in 2010 by the AAG that captured data for $70 \mathrm{PhDs}$ awarded in 2009-2010 (so less than half the number awarded), reports that of those 70 new PhDs in Geography, $2.9 \%$ were Black or African American; $4.3 \%$ were Hispanic or Latino; $12.9 \%$ were Asian. International students (non US citizens) were a separate category, accounting for $11.9 \%$ of the degrees (Solís and Adams 2011). So based on this admittedly partial information, there may be some increasing participation and success on the part of Asian and Hispanic or Latino doctoral students, but it is clear that doctoral education in Geography in the US still appears to be very white. Increased diversity in the discipline's faculty ranks is most likely to come from increasing diversity at the PhD level. The AAG's 2010 Survey reported that while $30.6 \%$ of all Geography faculty (all ranks) in the US are women, only $2.5 \%$ are Black or African-American, and $1.2 \%$ are Hispanic or Latino (AAG 2010), so Geography has a long way to go before it can be considered reflective of the nation's diversity (Adams et al. 2014; Solís et al. 2014). ${ }^{1}$

US doctoral programs in Geography share some common structural features, though there is great variation in exact specifications. Each $\mathrm{PhD}$ program

\footnotetext{
$\overline{1}$ I gratefully acknowledge the assistance of Dr. Patricia Solís, Director of Research and Outreach for the AAG, who helped me find and interpret some of these data.
}

and its structure will be subject to regulation and oversight by bodies within the university (such as an overarching Graduate School or Graduate College) and by other entities such as accreditation authorities. To describe the structure of US $\mathrm{PhD}$ programs in Geography requires some generalizing about the typical program. So, it might be useful to trace the organization of a typical program through the progress of a student. The main recruitment cycle for doctoral programs entails a formal application process, usually in the fall and early winter of the year prior to that for which admissions are made. Applications may come from students already in the department (perhaps pursuing a Masters degree) or from outside, and from US and non-US applicants. In most cases there are fees payable by each applicant. These vary across institutions but tend currently to be somewhere between US\$30 and US\$100, and are usually non-refundable. Some universities will waive the fee in certain cases. Each application is processed by a central Graduate School or College and undergoes a formal review by representatives of the program's faculty who typically will decide admissions, allocate funding, and may also coordinate the program's recruitment efforts. Many programs require doctoral students to possess a Masters degree prior to commencing doctoral study, but a few do not.

All programs in the US expect doctoral students to complete some coursework. This may include a suite of required courses, either specified or selected from a menu, offered within the discipline. In many programs, students are expected to also take some coursework in one or more other disciplines or in relevant interdisciplinary programs. It is not uncommon for the first year or 2 years of a US doctoral program to be spent completing coursework. The coursework is usually regarded as laying the foundations (be they theoretical, methodological, linguistic, empirical), for the student's research. In the US, it is quite common for a Geography doctoral student to have previous degrees in other areas, so a student may in fact be learning the discipline for the first time in his or her doctoral program. This is likely a significant difference from the situation in other national contexts, and may in part be explained by the fact that in the US Geography is an unfamiliar subject to many high school graduates and is typically only "discovered" during a student's undergraduate years or subsequently. 
In many cases, even before starting a doctoral program, a student will have selected his or her primary faculty advisor or supervisor. In other cases, students can defer selecting an advisor until their first year or so in their program. Once coursework has been completed, students in US doctoral programs will typically proceed to take some kind of examinations that serve to mark the end of the coursework phase and the beginning of the independent research phase of the degree. These exams are variously known as qualifying exams ("quals"), comprehensive exams ("comps"), preliminary exams ("prelims"), or candidacy exams. Again, while these exams are ubiquitous, the exact way they are structured varies widely from program to program. Usually there is a written component and an oral component. In some cases students may take common written exams, in others they may be individually designed. The exams may be closed or open book, and they may last a few hours or several days or even weeks. The oral component typically entails a several hour meeting of the student with his or her faculty committee. This advisory committee will be led by the student's primary advisor but typically includes two or three other faculty from Geography plus one or more faculty from other disciplines. The committee is responsible for passing or failing the student—either formally admitting the student to candidacy or not. A doctoral candidate is sometimes also called "ABD" standing for "all but dissertation". A doctoral student is also expected before, during, or after the exams, to develop a research proposal, which is vetted (the mechanisms and timing will vary) by the advisor and the committee. The expectations, in terms of content and detail, of the proposal vary from program to program, and even from advisor to advisor. Often, the proposal will be formatted so as to be easily developed for a submission to a funding agency—such as the National Science Foundation.

Each doctoral student conducts a major research project that may take years. Indeed, the average age of $\mathrm{PhD}$ recipients in the US in the social sciences or the earth sciences is over 30 years (NSF 2010). The major work undertaken by a doctoral student is a dissertation. This document, or parts of it, are often revised multiple times according to the advisor's recommendations. Each university has rules about the acceptable format and structure of dissertations, with many institutions accepting electronic dissertations as well as traditional paper documents. Increasingly, programs accept and encourage students to produce dissertations composed of chapters that are distinct papers or manuscripts. It is usually stipulated that a certain number of the chapters (often 3 or 4 ) be submitted and/or accepted for publication in peer-reviewed journals (and which journals are acceptable may be defined). There is growing interest in this so-called multi-paper dissertation in the US and there is some debate about the pros and cons of this type of dissertation and about the emerging norms in this area.

Students in Geography doctoral programs may be full-time or part-time, and many receive some kind of assistantship or fellowship that will also typically cover the fees for tuition. The most common form of assistantship is probably the teaching assistantship in which the doctoral student has instructional responsibilities for a certain number of hours a week (20 h is standard). Again, the exact nature of the responsibilities varies widely across programs and even within programs. More advanced doctoral students may have complete responsibility for an undergraduate course, for example. Research assistantships usually entail working on a faculty member's research project and such positions may be funded as part of a faculty member's grant or grants. Students on fellowships often do not have any set duties assigned to them, though this too varies. Student funding-be it in the form of assistantships or fellowships, may be awarded by the university or it may come from extramural sources, won by either the student or a faculty member. Whether or not any funding brings with it health insurance is another important factor, and again this varies. The nature of funding is a contentious issue in many programs. Most programs have policies guaranteeing internal funding to doctoral students for a specified number of years. A survey with 34 responding geography departments conducted in 2006 noted the average period of support for $\mathrm{PhD}$ students was 3 years (Turner and Sinha 2006).

In terms of trends, it seems that the overarching trend is the ever more systematic effort to provide greater professionalization for students. Many Geography doctoral programs now have formal courses designed to help students succeed in teaching, in seeking external research funding, and to generally enhance their understanding of the norms and expectations of academe. Much of these efforts were spurred directly or indirectly by national initiatives in the 1990s, notably The Pew Foundation's Preparing 
Future Faculty initiative that was launched in 1993 in collaboration with the Council of Graduate Schools, The National Science Foundation, and the Association of American Colleges and Universities (see The Preparing Future Faculty Program) (Solem and Foote 2004; Golde and Dore 2001). This initiative facilitated conversations and developments on many campuses, elements of which have been extended and elaborated by the AAG through its Healthy Departments Initiative and through the Enhancing Departments and Graduate Education (EDGE) program (Lawson 2004; Solem and Foote 2009). The initiatives began with paying attention to strategies for improving the quality of teaching by future faculty and with preparing doctoral students for the diverse institutional settings (not just research universities) in which most would be working after the PhD. More recently attention has shifted to include strategies to navigate very tight job markets within academe and for obtaining employment outside academe. In part this is addressing the situation highlighted by the National Association of Graduate and Professional Students Survey of Graduate Students, in which it was found that Geography $\mathrm{PhD}$ student respondents were much less satisfied with the advice and preparation for careers outside academe than they were for academic careers (NAGPS 2001). Certainly, many US doctoral programs in Geography now include such elements in their doctoral programs.

The ramifications of the economic recession for doctoral students are serious and multiple. Many US universities and colleges face painful budget pressures and, even in those institutions where the pressures might not be so severe, university administrators can use the current climate to push various restructuring programs in the name of cost savings. Given that faculty governance is often more an ideal than a reality on US campuses, this often means administrations' priorities are reflected in increasing class sizes and a shift to a greater proportion of teaching being done by contingent (non-permanent, often not full time) instructors, many of whom are often newly-minted PhDs with limited options for employment. Tenure track jobs are becoming less and less the norm. $\mathrm{PhD}$ graduates in the US are facing a rapidly changing environment and one for which few of them and even fewer of their advisors are prepared.

\section{References}

AAG. (2006). Geography Degrees Conferred in the US, 1947-2006. http://www.aag.org/galleries/default-file/ USGeographyDegrees.pdf.

AAG. (2010). AAG Survey of Geography Departments in North America. http://www.aag.org/cs/projects_and_programs/ disciplinary_data/aagcollected_data_from_supplemental_ surveys.

AAG Diversity Task Force. (2006). Final report: An action strategy for geography departments as agents of change. http:// www.aag.org/galleries/default-file/diversityreport.pdf.

Adams, J., Solís, P., \& McKendry, J. (2014). The landscape of diversity in U.S. higher education geography. The Professional Geographer, 66(2), 183-194.

Association of American Geographers (AAG). (2011). Guide to programs in the Americas 2010-2011. Washington DC: Association of American Geographers.

Golde, C. M., \& Dore, T. M. (2001). At cross purposes: What the experiences of doctoral students reveal about doctoral education (A report prepared for The Pew Charitable Trusts, Philadelphia, PA). www.phd-survey.org.

Lawson, V. (2004). Healthy departments, healthy discipline. President's column. AAG Newsletter, 39(8), 3-4. http:// www.aag.org/healthydepartments/ed_project_data/AAG news_HD.pdf.

National Association of Graduate and Professional Students. (2001). National doctoral program survey—results. http:// www.nagps.org/survey2000.

National Center for Education Statistics. (2011). Digest of education statistics. U.S. Department of Education, Washington DC. http://nces.ed.gov/programs/digest/d11/tables/dt11_288.asp.

National Science Foundation. (2010). Doctoral recipients from U.S. Universities, summary report 2010 (National Science Foundation, Arlington, VA). http://www.nsf.gov/statistics/ sed/start.cfm.

Solem, M. N., \& Foote, K. E. (2004). Concerns, attitudes, and abilities of early-career geography faculty. Annals of the Association of American Geographers, 94(1), 889-912.

Solem, M., \& Foote, K. (2009). Enhancing departments and graduate education in geography: A disciplinary project in professional development. International Journal of Researcher Development, 1(1), 11-28.

Solís, P., \& Adams, J. (2011). AAG departmental data survey finds modest diversity gains within academic geography. AAG Newsletter, 46(4), 4.

Solís, P., Adams, J., Duram, L., Hume, S., Kuslikis, A., Lawson, V., et al. (2014). Diverse experiences in diversity at the geography department scale. The Professional Geographer, 66(2), 205-220.

Thurgood, L., Golladay, M. J., \& Hill, S. T. (2006). U.S. Doctorates in the 20th Century (Special report. National Science Foundation, Arlington, VA). http://www.nsf.gov/ statistics/nsf06319/pdf/nsf06319.pdf.

Turner, B. L., \& Sinha, D. (2006). Survey of graduate stipends in US geography programs. http://www.aag.org/healthy departments/healthy_enrollment.cfm.

The Preparing Future Faculty Program. Washington, DC: The Council of Graduate Schools. http://www.preparingfaculty.org/. 